\title{
Seasonal Behaviour of Mesoscale Eddy Trajectories in the North Indian Ocean Based on Satellite Altimetry
}

\author{
Shailesh Mohan Pednekar \\ Ocean Science Group, National Centre for Polar \& Ocean Research, Ministry of Earth Sciences, Headland Sada, Vasco-da-Gama, \\ Goa, India \\ Email: shailesh@ncpor.res.in, sm_pednekar@yahoo.com
}

How to cite this paper: Pednekar, S.M. (2022) Seasonal Behaviour of Mesoscale Eddy Trajectories in the North Indian Ocean Based on Satellite Altimetry. International Journal of Geosciences, 13, 93-114. https://doi.org/10.4236/ijg.2022.132006

Received: November 12, 2021

Accepted: February 19, 2022

Published: February 22, 2022

Copyright () 2022 by author(s) and Scientific Research Publishing Inc. This work is licensed under the Creative Commons Attribution International License (CC BY 4.0).

http://creativecommons.org/licenses/by/4.0/ (c) (i) Open Access

\begin{abstract}
In the north Indian Ocean (NIO), maps of sea level anomaly from satellite altimetry were analysed from January-1995 to December-2000. The study attempted to trace the trajectories of the individual mesoscale anomalies manually and to understand seasonal changes in terms of phase speed. Mesoscale anomalies are detected as concentric circular shapes and diameters of $\sim 90 \mathrm{~km}$ to $600 \mathrm{~km}$ and the minimum 30 days life cycle. Relatively higher eddy kinetic energy was noticed in the northwestern region of the NIO. Individual mesoscale anomalies, namely positive (warm, anticyclonic eddies) and negative (cold, cyclonic eddies) showing travelling direction westward in the NIO basins. In autumn, the number of negative anomalies detected is more than positive anomalies and vice versa during summer. The westward propagating positive (negative) anomalies in the Arabian Sea start appearing in winter (spring) along (away from) the west coast of India and west of $65^{\circ} \mathrm{E}$; individual anomalies move to the west in spring/summer/autumn and collide along Somalia's \& Arabian coast. A group of positive (negative) anomalies trajectories appears as a tail at the southern tip of India are located west of the Laccadive ridge in winter (summer to autumn) associated with $\mathrm{LH}$ (LL). The Bay of Bengal (BB) trajectories show southwestward in northern $\mathrm{BB}$, westward in central $\mathrm{BB}$ and northwestward in southern $\mathrm{BB}$; individual anomalies are appearing along the west coast of Andaman \& Nicobar ridge. The zonal phase speed decreases away from the equator, and the magnitude varies longitudinally in each season in the form of a wave-like pattern propagating westward from autumn to summer; the life cycle of the wave is almost 365 days (a year). The theoretical phase speed of the first mode of the baroclinic Rossby waves is quite similar to that of averaged zonal speed. Therefore mesoscale anomalies (eddies) are embedded into the large waves like phenomenon (Rossby
\end{abstract}


waves), responsible for creating high variability and EKE in the region of NIO along the western boundaries.

\section{Keywords}

Remote Sensing, Satellite Altimetry, North Indian Ocean Circulation, MSLA, Mesoscale Eddy, Seasonal Variability, Positive and Negative Anomalies

\section{Introduction}

The North Indian Ocean (NIO) is unique as compared with the other major oceans. It is more complex and least-understood oceanographically. One of the consequences of the Indian Ocean geography [1] is that the NIO undergoes intense monsoon winds reverses the pattern annually. The seasonal reversing of monsoon winds drives the oceanic currents in the upper ocean. This different atmospheric forcing produces dramatic changes in physical, chemical, and biological characteristics in the top layers of the water column [2] [3] [4]. [5] studied the seasonal changes in circulation that undergo dramatic changes. During the northeast (NE) monsoon from December to February, the north equatorial current (NEC) is westward, with one branch travelling poleward along the west coast of India as west India coastal current (WICC [6]). The northeasterly winds drive the southward flowing Somali current (SC). Due to strong monsoonal wind, the SC reverses its direction poleward during the southwest (SW) monsoon from June to August. The eastward flowing Indian monsoon current (IMC) appears in the equatorial region and a weak poleward EICC appears in the south. During transition periods between monsoons (March to May and September to November), an eastward equatorial jet (EJ [7]) develops along the equator. This current system is represented schematically in Figure 1(a) and Figure 1(b).

The formation and the propagation of mesoscale eddies influenced the ocean's circulation. These mesoscale eddies are estimated as significant heat transports in the oceans, affecting regional transport [8]. The cyclonic eddies bring the nutrient-rich cool bottom waters to the surface and support biological processes, resulting in greater fish yields eventually, whereas the warm-core eddy results in downwelling and is known as ocean deserts. In recent years a considerable amount of data were obtained by GEOSAT satellite altimetry [9] and high-precision TOPEX/Poseidon (T/P) altimetry provided new insight since 1993 in the study of mesoscale variability and dynamics. In the Pacific Ocean, altimeter data have been used tremendously by the researchers showing significant progress in the studies of mesoscale eddies [10] [11] [12]. Western boundary currents such as Gulf streams and Brazil current in the Atlantic, Kuroshio and East Australian Current in the Pacific, the Agulhas Current in the southern Indian Ocean and the Somali current (SC) and east India coastal current (EICC) in the NIO having the potential to generate warm and cold-core eddies which are an integral part of 

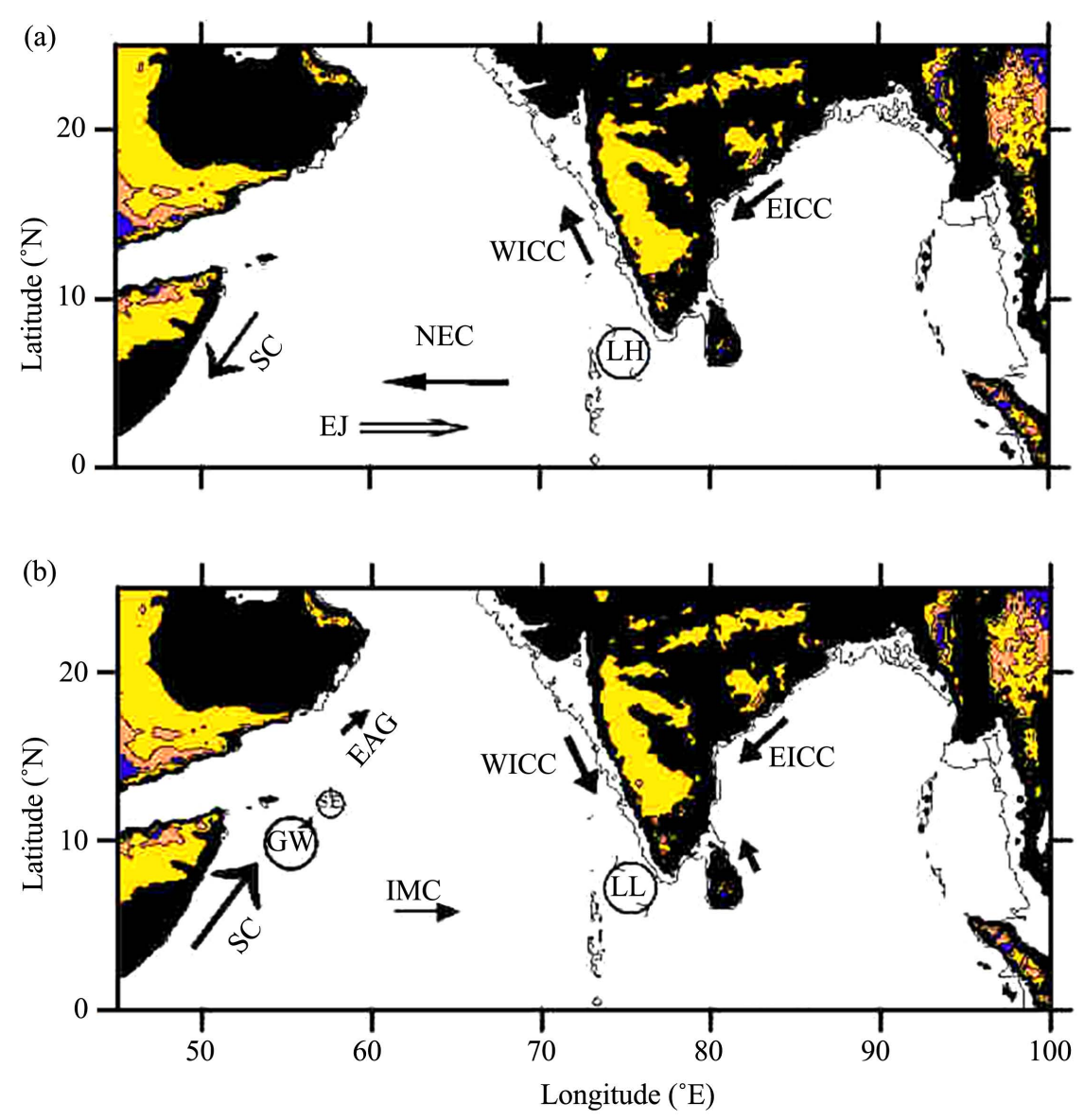

Figure 1. Schematic diagram showing the circulation in the north Indian Ocean during (a) Winter (except for the equatorial jet (EJ), which is observed in spring and fall), and (b) Summer. The abbreviation is as follows: NEC, north equatorial current; SC, Somali current; WICC, west India coastal current; EICC, east India coastal current; LH, Laccadive high; EJ, equatorial jet; LL, Laccadive low; EAC, east Arabian current; IMC, Indian monsoon current; GW, Great Whirl; SE, Socotra eddy.

the general circulation of the ocean, although few studies show the existence of eddies during the sampling period [13] [14].

Chelton [15] studied nonlinear mesoscale eddies in the global ocean using 16 years period SSH of the AVISO based on an automated eddy identification procedure. Several studies were conducted in the NIO basins namely the Arabian Sea (AS) and Bay of Bengal (BB). [16] analyzed SSH of the T/P satellite from October 1992 to October 1998 over the AS. Westward propagating annual Rossby waves generated from the western side of the Indian subcontinent is responsible for seasonal changes between $6^{\circ}$ and $10^{\circ} \mathrm{N}$ due to continuously forced by the action of the wind-stress curl over the central AS. The impact of these waves on the coastal circulation of the AS has been relatively well studied [17] [18] [19]. [20] looked at how the reflection of semiannual Kelvin waves at the eastern limit of the Indian Ocean might impact the western AS upwelling region. Between June and September, the northwestern Indian Ocean reveals a relatively higher energetic eddy field during the southwest monsoon season. [21] analyzed 
the seasonal and inter-annual variability of the eddy characteristics and their trajectories in the northwestern Indian Ocean using altimeter SSH observations from 1993 to 2014 and [22] studied inter-annual variability of mesoscale eddy occurrence in the western AS based on MODIS-Aqua sea surface height anomalies. In the AS, the number of eddy formations can broadly indicate the good or bad monsoon years [23].

In the BB basins, [24] detected oceanic eddied from TOPEX and in-situ observation. The life cycle of eddies along the western boundary of the BB and their implications carried out by [25] and [26] studied the role of mesoscale eddies on the variability of biogenic flux in the BB. Using statistical analysis on 22-years of altimetry data [27] studied the eddy properties in the BB. During the strong monsoon year of 2019 interface between mesoscale eddies and synoptic oscillations was revealed by [28] and found the difference in eddy characteristics between the western and eastern $\mathrm{BB}$, where eddies in the eastern $\mathrm{BB}$ are dominated by coastal Kelvin wave dynamics and topographical influences, and the eddies in the western BB are modulated by EICC dynamics. [29] pointed out that the $\mathrm{BB}$ dynamics is influenced by the Indian Ocean circulation because the southern bay is open to the NIO, and due to the monsoon conversion region. [30] suggested based on the reduced gravity model that the long Rossby waves excited by the remotely forced Kelvin waves contribute to the seasonal variability of the local BB.

Several studies above have shown trajectories and characteristics of individual mesoscale eddies in the NIO based automated manner however in this paper we adopted a manual method to digitised individual trajectories as performed in the Pacific region [10] [11] [12] using 10 days interval synoptic maps of satellite altimetry only for five years period. The main objectives in this connection, we lack knowledge on mesoscale eddies seasonal variability and their generation, propagation, and decay processes on the temporal and spatial scale. Nevertheless, it is essential to investigate the seasonal trajectories of mesoscale eddies to understand seasonal changes in terms of their phase speed to know better circulation in the NIO. In the present study, an attempt has been made to identify manually the generation and decay of individual anomalies (mesoscale eddies) seasonally and variability of the zonal phase speed. The data and methods used are described in Section 2, while Section 3 briefly explains the results and Section 4 gives the summary and conclusions.

\section{Data and Methods}

\subsection{Maps of Sea Level Anomaly Data}

The following data have been used to fulfil the objective of the study. The satellite altimeters provide broad exposure in space and high resolution in time gives an essential tool to examine the spatial and temporal evolution of the mesoscale eddies. The AVISO (Archiving, Validation, and Interpretation of Satellites Oceanographic) Map of Sea Level Anomaly (MSLA) altimeter product released every 
10 day's on a $1 / 4^{\circ} \times 1 / 4^{\circ}$ grid box for approximately six years (January 1995 to December 2000) is used. The ERS-1 \& ERS-2 data are fitted to the more precise $\mathrm{T} / \mathrm{P}$ data using a global minimisation of ERS and T/P dual crossover differences [31] [32]. MSLA is obtained using an improved space and time objective analysis method [32]. Merging data from the different satellites provide space and time sampling of ocean features, especially mesoscale eddies. Also, the monthly temperature and salinity profiles mainly extracted from the online climatology [33] [34] are used for validating filtered SSH anomaly products. Global Ocean Depth \& Land Elevation (ETOPO5) bathymetry data in a uniform and complete latitude/longitude 5-min interval grid resolution were also used in this study (NOAA/NGDC, 1988). All elevations are given in meters, positive above sea level and negative below. These data were provided by the National Center for Atmospheric Research (NCAR).

\subsection{Methods during the Analysis of Data}

Relative sea-level anomaly or filtered SSH anomaly were obtained, filtering out the error due to space and time that is the low frequency (LF) part from MSLA is eradicated. The LF mean background is calculated as follows; approximately three cycles are averaged for each month in each year. The monthly mean is prepared using six years of cycles, the running mean (moving average) was calculated in space $(1000 \mathrm{~km}$ latitude $\times 1000 \mathrm{~km}$ longitude) and with time (five months moving averages) to get the smooth mean background. These smoothed monthly mean backgrounds are finally used to remove the errors in space and with time from each original MSLA cycle according to the month of the particular cycle [35]. The filtering aims to reduce small-scale variations as [36] showed that accuracy much better than $\pm 10 \mathrm{~cm}$ is required to study the circulation. Satellite altimetry technology validated calculating the geopotential anomaly using hydrographic data from Levitus climatology, following [37] is compared with the filtered SSH anomaly derived from satellite altimetry along $5.5^{\circ} \mathrm{N}$ zonal section in the NIO as an example is shown in Figure 2(a) for January (winter) and Figure 2(b) for July (summer). The two plots show perfect agreement with each other during the two monsoon seasons. However, there is $\sim 5 \mathrm{~cm}$ deviation from each other due to the spatial resolution of hydrographic data (is $1^{\circ}$ ) and MSLA (is $1 / 4^{\circ}$ ). Figure 2 confirmed that it is possible to use altimetry satellite technology in ocean study to understand mesoscale features in ocean circulation.

The following procedure was adapted to trace mesoscale eddy trajectories. The data were contoured on a cycle-by-cycle basis to reveal the significant variations in the target area and elucidate eddies' movement. The contouring method is used as an automated gridding procedure to ensure objectivity in identifying eddies and to expedite the analysis. Rings were tracked manually on a $1 \mathrm{~cm}$ interval contoured map (minimum contour traced was $\pm 10 \mathrm{~cm}$ ) by identifying them at a regular time and space interval to get the better resolution to traced mesoscale eddies. Then eddy trajectory is traced in each 10 day's interval cycle 


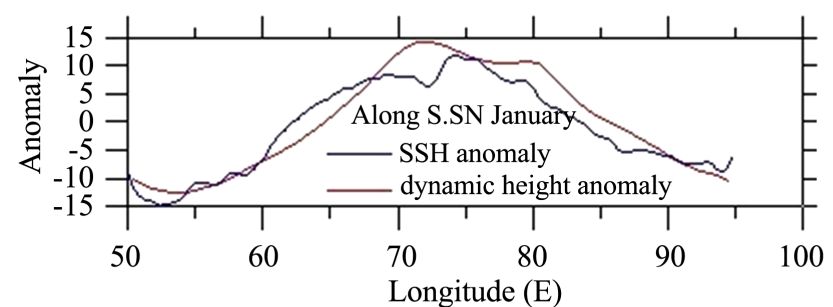

(a)

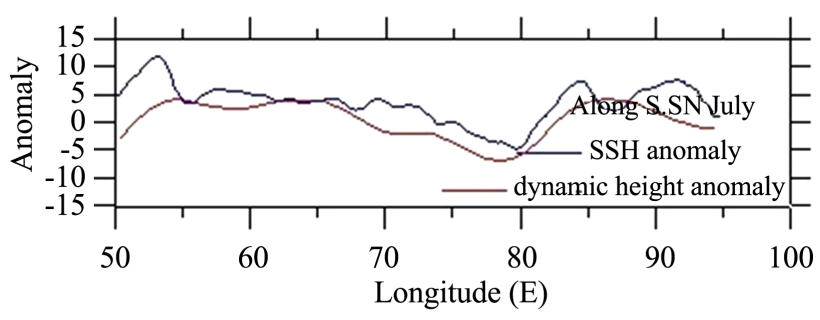

(b)

Figure 2. Comparison maps between SSH anomaly from altimetry (cm, Blue line) with geopotential anomaly calculated using [33] [34] (dyn-cm, Redline) along $5.5^{\circ} \mathrm{N}$ zonal sections, left panel (a) for January, and right panel (b) for July in the north Indian Ocean.

till it disappears. Manually approximate concentric circle-like shapes, the horizontal diameter should be between $100 \mathrm{~km}$ to $600 \mathrm{~km}$, and temporal scale is more than two cycles, at least three 10 day's interval MSLA cycles (minimum) required tracing from April 1995 to December 2000. If the high and low variability region does not continue the following cycle, it is considered a generation or decay stage of the particular individual eddy trajectories.

In the case of seasonal traces, the trajectories may continue from the end of one season to the beginning of another season. In such a situation, the trajectory will be ended in that particular month of the season. Mesoscale eddy with $<90$ $\mathrm{cm}$ diameter is not considered in the current investigation. The amplitude and size of eddies depend on the spatial resolution of the SSH field and therefore we adopted the 30 days time window by considering the persistence of the mesoscale eddies. While tracing the trajectory of the eddy, the central of eddies is defined by the local maximum and minimum of the SSH anomaly and traced in back and forth 10 day's interval cycles. Sometimes, the diameter of particular eddies may vary depending on the cycles; even though it looks small or weak in some cases, it is considered a continuation of the life cycle. The following sections give the outcome of this analysis. Further in this study, composite seasonal diagrams are made averaging three months for each season, namely, autumn (September to November), winter (December to February), and spring (March to May), summer (June to August).

\section{Results}

Standard deviation (SD) calculated using Equation (1) in the NIO basins indicates energetic and high activity regions along the western boundary, the southern tip of India, and along the east coast of India (Figure not included). Wondering why such a high activity region exists in these regions, is it due to remote forcing or something else plays the role for their existence. The eddy kinetic energy (EKE) field distribution is essential to recognise the regional high EKE. Further to understand who is responsible for high variability, we traced individual anomalies from their generation to the decays stage to evaluate the activity and behaviour of individual anomalies in different seasons. Finally, zonal speed and meridional propagation speed are compared with the theoretical speed of 
the first phase of Rossby waves and understood the seasonal behaviour of mesoscale eddies in conclusions.

$$
S D=\sqrt{\frac{\sum\left(x_{i}-\mu\right)^{2}}{N}}
$$

where $S D$ is standard deviation, $N$ is the total number of observation, $x_{i}$ is the value in the data distribution and $\mu$ is the sample mean.

\subsection{Eddy Kinetic Energy (EKE)}

The EKE, the energy of motion estimated as propagation characteristics of anomalies, is important to understand their generation and spread mechanism. Using fluctuation components of the geostrophic surface velocity derived from filtered MSLA, EKE is calculated [38]. EKE is associated with the turbulent part of the flow of fluid. A large part of the AS and the BB exhibit a low EKE (less than $100 \mathrm{~cm}^{2} \cdot \mathrm{sec}^{-2}$ ). The distribution of EKE helps in identifying the regions with the most energetic temporally varying fluctuations. [39] presented the EKE distributions over the world oceans using ship-drift data: since then, no similar estimates have been made for the tropical Indian Ocean. Recently, [40] attempted to present mean EKE distribution on $2^{\circ} \times 2^{\circ}$ grid boxes using satellite-tracked drifting buoys deployed in the tropical Indian Ocean. Therefore the EKE distribution presented here to refine those presented by [39] and [40]. The distribution of EKE during different seasons is shown in Figures $3(\mathrm{a})$-(d) on $1 / 4^{\circ} \times 1 / 4^{\circ}$ grid box. Generally, along the equatorial belt, the EKE is large (Figure 3). For autumn (Figure 3(a)), there is a shift and weakening of EKE along the Somali

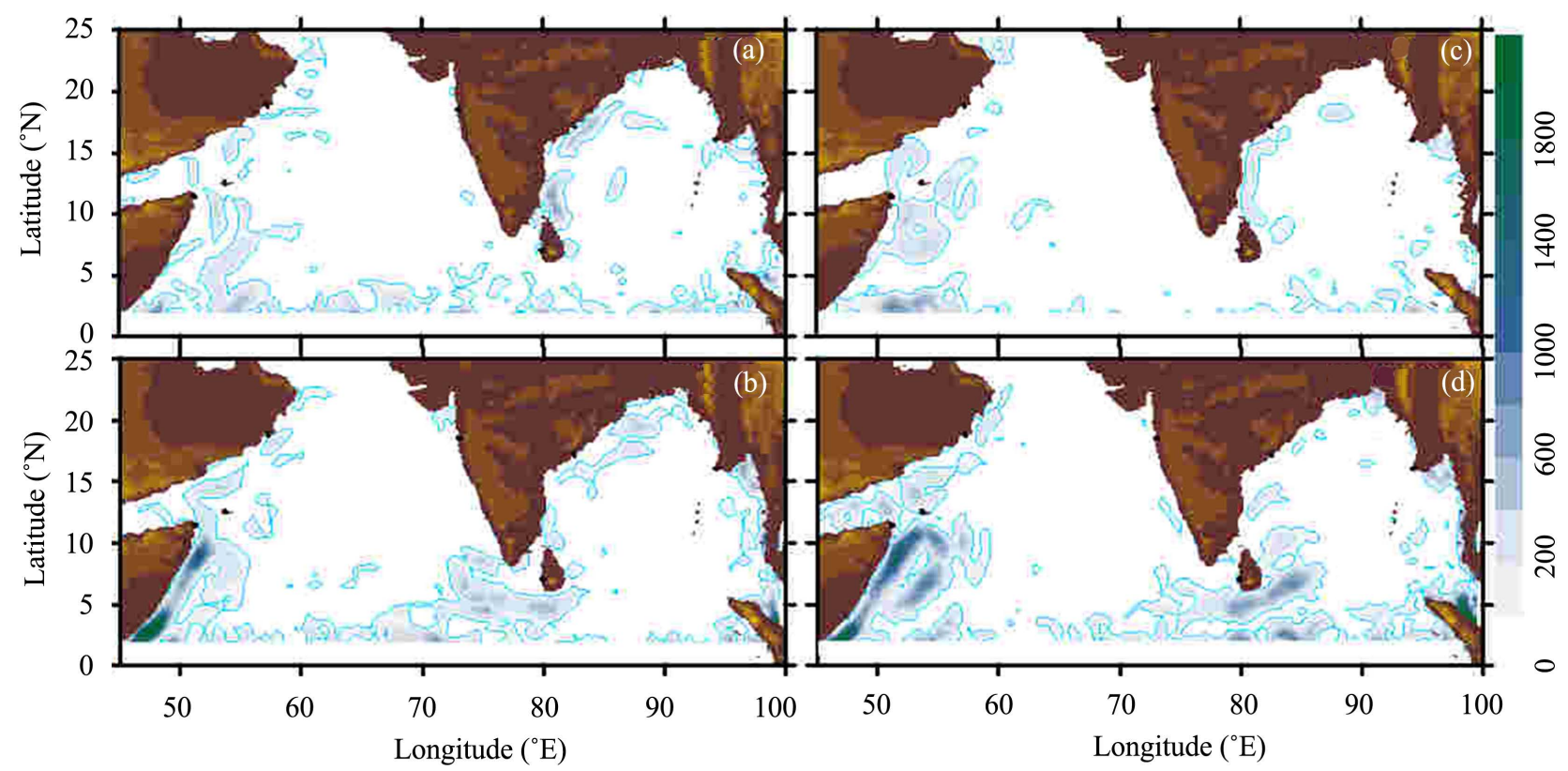

Figure 3. The eddy kinetic energy distribution $\left(\right.$ in $\mathrm{cm}^{2} \cdot \mathrm{sec}^{-2}$ ) at the sea surface is estimated from the composite maps of filtered MSLA altimeter data. Contour is shown of $100 \mathrm{~cm}^{2} \cdot \mathrm{sec}^{-2}$, and scale bar shown interval of $100 \mathrm{~cm}^{2} \cdot \mathrm{sec}^{-2}$. (a) Autumn; (b) Winter; (c) Spring; (d) Summer. 
coast. Along the east coast of India, EKE increases and becomes large ( $>600$ $\left.\mathrm{cm}^{2} \cdot \mathrm{sec}^{-2}\right)$. The signature of EKE is negligible in central AS and BB throughout annually $\left(<100 \mathrm{~cm}^{2} \cdot \mathrm{sec}^{-2}\right)$. In winter (Figure $\left.3(\mathrm{~b})\right)$, EKE developed and reaches the maximum ( $\left.>2000 \mathrm{~cm}^{2} \cdot \mathrm{sec}^{-2}\right)$ likewise in summer (Figure $3(\mathrm{~d})$ ). The large energy patch $\left(>500 \mathrm{~cm}^{2} \cdot \mathrm{sec}^{-2}\right)$ begins south of Sri Lanka and extends up to the southern tip of India. The northern BB is showing energy greater than 500 $\mathrm{cm}^{2} \cdot \mathrm{sec}^{-2}$. The loss in EKE found during autumn along the east coast of India is reduced to $<200 \mathrm{~cm}^{2} \cdot \mathrm{sec}^{-2}$ in winter. In spring (Figure $3(\mathrm{c}$ )), EKE is lost to $<300$ $\mathrm{cm}^{2} \cdot \mathrm{sec}^{-2}$ and is widely scattered along the Somali coast. In Figure 3(d) (summer), EKE is developed attaining to maximum $\left(>2200 \mathrm{~cm}^{2} \cdot \mathrm{sec}^{-2}\right)$ along the Somali coast. There is shifting towards east from winter to summer and increased eddy energy south of Sri Lanka up to $>900 \mathrm{~cm}^{2} \cdot \mathrm{sec}^{-2}$. Along the east and west coast of India week, energy signature depicted.

The distribution of the EKE along the Somali basin shows larger energy $\left(>2000 \mathrm{~cm}^{2} \cdot \mathrm{sec}^{-2}\right.$ ) during winter (Figure 3(b)) and in summer (Figure 3(d)). Comparison of EKE estimated by [39] shows that they agree qualitatively but not quantitatively. Both show the highest energy in the western basin and the lowest eddy energy in the AS and the BB. Again, both estimates show high energy at the equator. Another difference is in the magnitude of EKE in the AS and the BB, where [39] report $600 \mathrm{~cm}^{2} \cdot \mathrm{sec}^{-2}$ and filtered SSH estimate is around $100 \mathrm{~cm}^{2} \cdot \mathrm{sec}^{-2}$. [40] also found the difference of approximately $200 \mathrm{~cm}^{2} \cdot \mathrm{sec}^{-2}$ was also noted by [41] in the western North Atlantic. He attributed it to an error of about 20 $\mathrm{cm} \cdot \mathrm{sec}^{-1}$ in the ship drifts, which translates to an error of $200 \mathrm{~cm} \cdot \mathrm{sec}^{-2}$ in EKE. High variability region associated with maximum EKE [42]. The EKE is remarkably high in the Kuroshio Extension region [39]. In addition, SD using filtered MSLA indicates energetic and high activity regions in western regions of both basins (the AS and the $\mathrm{BB}$ ). These high energies are associated with various current systems under monsoonal winds (Figure not included). These energetic regions are the Somalin basin with $\mathrm{SD}>18 \mathrm{~cm}$, the east coast of India with $\mathrm{SD}>$ $18 \mathrm{~cm}$, and the southern tip of India with SD $>11 \mathrm{~cm}$. East of the AS and the BB variability is very low $(<6 \mathrm{~cm})[43]$.

\subsection{Seasonal Trajectories of Anticyclonic Eddies in Each Basin of NIO}

The mesoscale eddies constitute the most energetic component of the variability of ocean currents. The variability of numbers of positive anomalies for each season is plotted in Figure 4 (solid red line). The total number of positive mesoscale anomalies traced during the period is 579 from generation to decay. In winter, the number of positive trajectories is less than in other seasons and gradually increases until summer through spring. The number of positive trajectories counts decreases from autumn until winter.

The seasonal life cycles of anticyclonic eddies are recognised, tracing back and forth in 10 days interval filtered SSH anomaly cycles from 1995 to 2000 is 


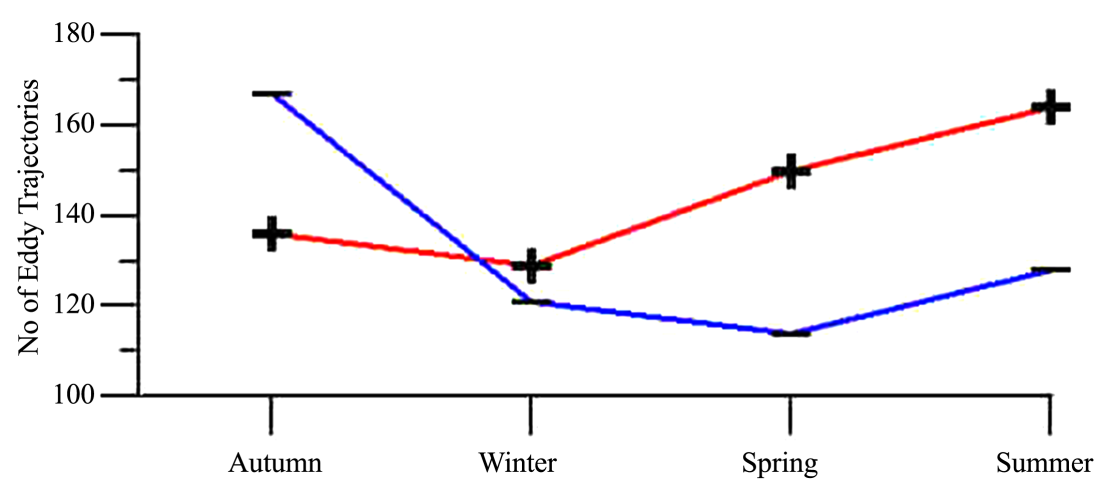

Figure 4. Seasonal distribution of the total number of generations of individual mesoscale eddy trajectories in the north Indian Ocean. Plus sign indicates positive anomalies, and a minus sign indicates negative anomalies.

represented in Figures 5(a)-(d). 579 anticyclonic eddies are traced, starting from their first appearance in the cycle and ending with the decay stage. In general, eddies travel westward direction and decays along the steep slope of the continent. Eddies could be travelling faster near the equator and slower away from the equator. The minimum life period is 30 days, and a maximum life period of 90 days is considered. Individual basins trajectories are described separately.

\subsubsection{Arabian Sea (AS) Basin}

The distribution of anticyclonic eddy trajectories is shown in Figures 5(a)-(d) as propagating tendency westward along the zonal section. In Autumn (Figure 5(a)), eddies were not traced along the west coast of India except a few near the mouth of the Gulf of Kutch and the southern tip of India and the grouped eddy trajectories along the Somalian and Arabian coast. In winter (Figure 5(b)), eddies appear to generate along the shelf of India's west coast and progress westward away from the continental shelf towards the centre of the AS basin, where the generation of eddies was less and spotted widely. Eddy trajectories appear as long tales near the southern tip of India and on the west of Laccadive ridge. These propagating cycles travel towards central AS in spring (Figure 5(c)), and eddies generation shifted after continental shelf break along the west coast of India. The two separate tales which are noticed in winter combined forming continues a group of trajectories. The generation and the propagation of eddy cycles continued in summer (Figure 5(d)) after passing through spring. It seems the group of eddies found in winter near the southern tip of India crosses or decays in spring (Figure 5(c)) due to the effect of shallow region of Laccadive ridge and regenerated on the western side of Laccadive ridge in spring approaches the east coast of Somalia in Summer (Figure 5(d)). Northern AS could be influenced by the intrusion of freshwater from the rivers and by high saline water from the Persian Gulf. Due to these characteristics, short terms (one month) life cycle eddies form along the Arabian coast in spring, which continues in summer and decays in autumn/winter. Further eddies moved towards the west, creating space 


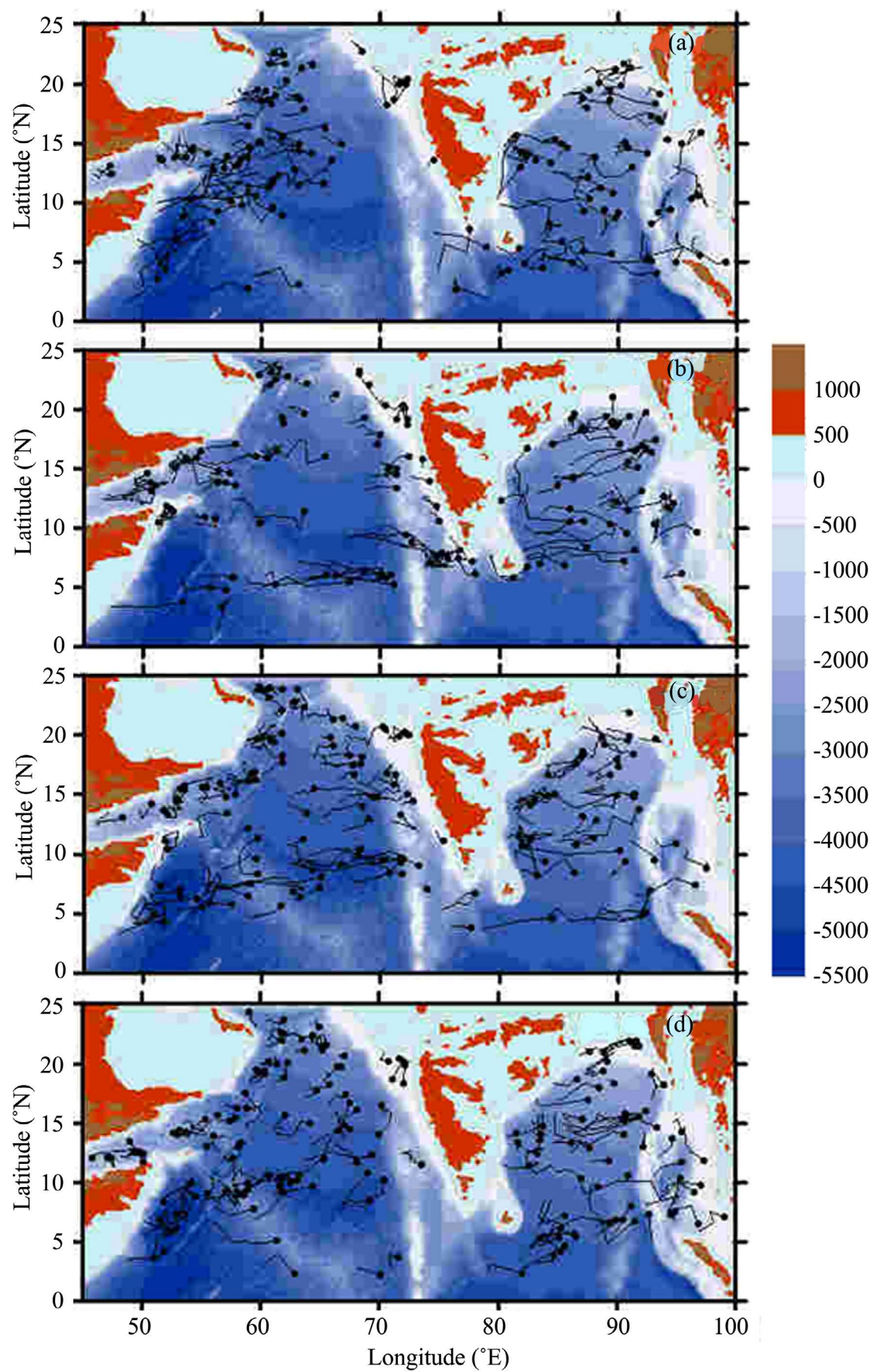

Figure 5. The six years of time series maps from 1995 to 2000 yielded tracings of anticyclonic eddies. Trajectories are shown in the right panel superimposed on bathymetry maps for different seasons. A solid circle indicates the starting position of anticyclonic eddies. (a) Autumn; (b) Winter; (c) Spring; (d) Summer.

along India's west coast (Figure 5(d)). The life cycle of these eddies generated in the AS seems to be more than 30 days. The trajectories of mesoscale eddies are affected mainly by the bottom topography, and the eddies tend to pass through the gaps. Eddy trajectories occupy most of the AS in summer except south of $5^{\circ} \mathrm{N}$. This may be due to strong summer monsoonal winds stress being pushed 
more northward, and by autumn, all the trajectories facing the wind in the opposite direction and collided or aligned with the Arabia coastal belt. Their backup remains up to autumn, and later, they decay during winter seems to be influencing the circulation in the south of AS by the formation and the propagation and decays of mesoscale eddies during winter.

[44] presented the evidence of an anticyclonic eddy in Laccadive High (LH) in southeastern AS. It was suggested that the LH resulted from an intense anticyclonic wind stress curl in southeastern AS during winter. They also noted the role of remote forcing in the formation of LH. Further, [45] indicated that the LH is comprised of multiple eddies. They also noted that the remote forcing in the formation of LH Laccadive eddies continuously covered by southern AS high [46] ultimately supplies energy to the Somalian region. The life cycle of these eddies is found to be more than two months. Several authors in Japan/East Sea have indicated the interaction of the eddy field with the bottom topography has been indicated by several authors in Japan/East Sea based on in situ studies [47] [48]. [18] revisited this idea. They suggested that the formation of the LH and Laccadive low (LL, which forms during summer at the exact location) are a consequence of westward propagating Rossby waves radiated by Kelvin waves propagating poleward along the western margin of the Indian subcontinents. Two processes, local wind stress curl and equatorially trapped Rossby waves are likely contributors to these currents [17]. It was suggested that the trajectories of eddies are affected by the bottom topography. Several authors in Japan/East Sea have indicated the interaction of the eddy field with the bottom topography has been indicated by several authors in Japan/East Sea based on in situ studies [47] [48]. It seems that the movement of mesoscale eddies is governed by the bathymetry effect apart from the other physical phenomenon.

It seems the AS circulation is influenced by the formation and propagation and decays of mesoscale eddies during winter. The generation and decays of eddies seem to be comparable with the earlier regional studies given below. It could be one of the reasons that LL supplies energy to the entire central AS for the formation of small-scale eddies. It seems energy is transferred from one season to another. Energy is carried forward to next season. These eddies are known as LL. The circulation in the AS is influenced by the formation and propagation of mesoscale eddies. These eddies are estimated as major transport of heat in the oceans. [44] presented the evidence of an anticyclonic eddy in Laccadive High (LH) in southeastern AS. It was suggested that the LH resulted from an intense anticyclonic wind stress curl in southeastern AS during winter. They also noted the role of remote forcing in the formation of $\mathrm{LH}$.

Further, [45] indicated that the LH is comprised of multiple eddies. They also noted the remote forcing in the formation of LH. Laccadive eddies continuously covered by southern AS high [46] ultimately supplies energy to the Somali region. The life cycle of these eddies is found to be more than two months. Several authors in Japan/East Sea have indicated the interaction of the eddy field with the bottom topography has been indicated by several authors in Japan/East Sea 
based on in situ studies [47] [48]. [18] revisited this idea. They suggested that the formation of the LH and Laccadive low (LL, which forms during summer at the exact location) are a consequence of westward propagating Rossby waves radiated by Kelvin waves propagating poleward along the western margin of the Indian subcontinents.

\subsubsection{Bay of Bengal (BB) Basin}

The area wised, the $\mathrm{BB}$ is smaller as compared to AS. The bay is divided into three zones, the northern $\mathrm{BB}$, the central $\mathrm{BB}$, and the southern $\mathrm{BB}$. The freshwater input from the rivers influences the northern $\mathrm{BB}$, the central $\mathrm{BB}$ is influenced by the winds, and the southern $\mathrm{BB}$ is affected by the intrusion of high salinity waters from the AS [49]. The seasonal map of positive mesoscale eddy trajectories is shown in Figure 5. In the northern BB, the positive anomaly trajectories appearing in winter (Figure 5(b)) near Burma continental shelf travelling in the southwest direction continue passing through spring (Figure 5(c)) travelling faster and decays in summer/autumn (Figure 5(a) and Figure 5(d)) along the shallow coastal region. In the central $\mathrm{BB}$, positive anomalies trajectories appear along the continental shelf of Andaman and Nicobar plateau in winter (Figure 5(b)), showing propagation direction as westward during spring/summer (Figure 5(c) and Figure 5(d)) and decays along the east coast of India. In the southern $\mathrm{BB}$, the positive anomalies trajectories are shown westward direction travelling towards east coast Sri Lanka in summer and winter (Figures 5(b)-(d)) generate west of $90^{\circ} \mathrm{E}$.

\subsection{Seasonal Trajectories of Cyclonic Eddies in Each Basin of NIO}

The variability of numbers of negative anomalies for each season is plotted in Figure 4 (solid blue line). The total number of negative mesoscale anomalies traced during the period is 530 from generation to decay. In winter, the count of positive and negative anomalies is almost equal and remains below the positive anomalies and increases gradually until summer through spring. While in autumn, the number of negative anomalies increases, reversing the summer pattern. Negative anomalies dominate positive anomalies count during autumn. Seasonal life cycles of cyclonic eddies are identified, tracing back and forth in 10 days interval filtered SSH anomaly cycles from 1995 to 2000 is represented in Figures 6(a)-(d). 530 cyclonic eddies are traced, starting from their first appearance in the cycle and ending with the decay stage. The mesoscale anomalies are travelling westward direction and decay along the steep slope of the continent. The minimum life period represented is 30 days, and the maximum life period is 90 days since we selected composition maps of three months for each season. Individual basins trajectories are described separately.

\subsubsection{Arabian Sea (AS) Basin}

Figure 6(a) shows the distribution of eddy trajectories during autumn. West of $65^{\circ} \mathrm{E}$ eddy trajectories identified in AS showing southwest direction. In winter 


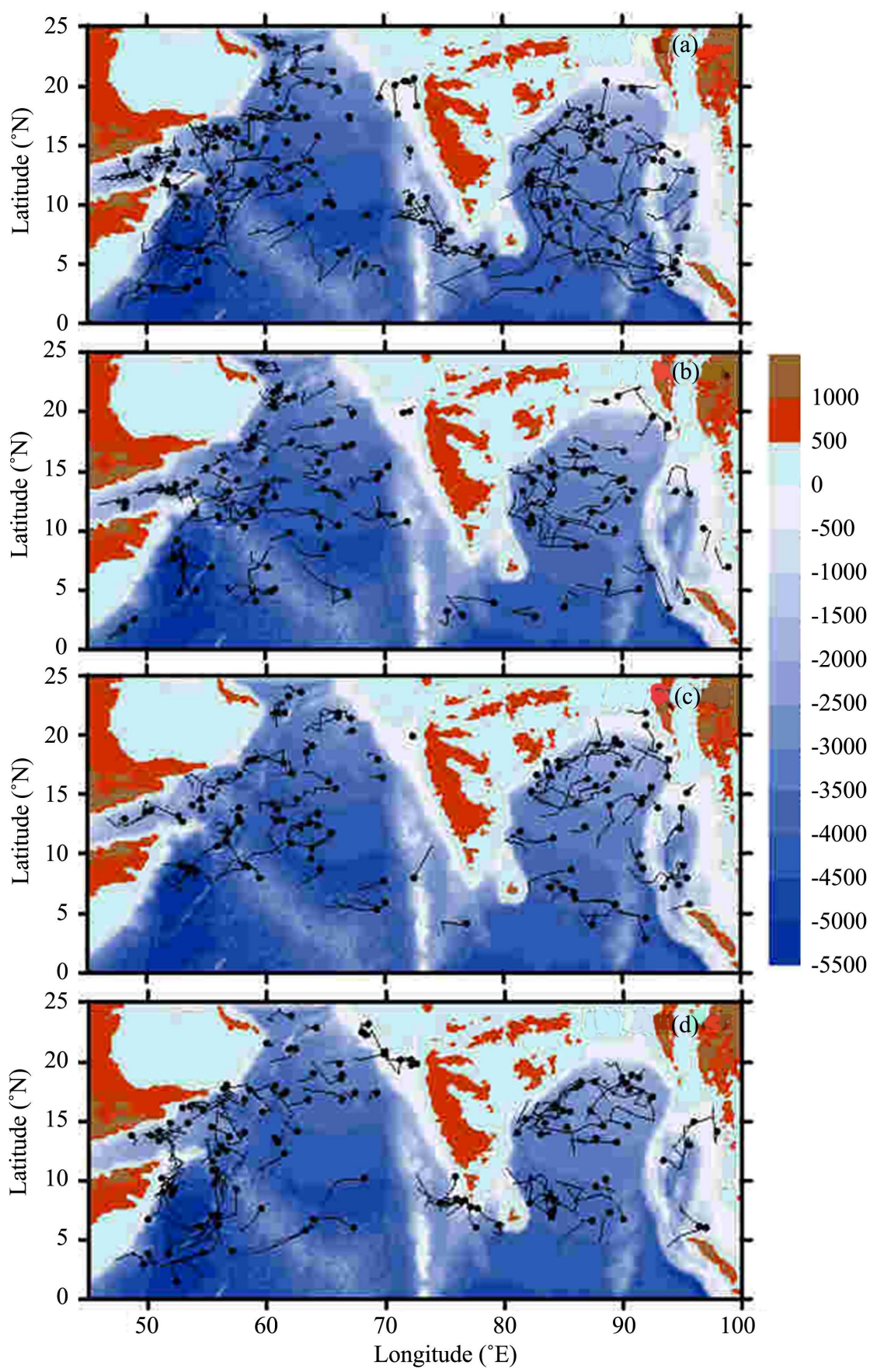

Figure 6. The six years of time series maps from 1995 to 2000 yielded tracings of cyclonic eddies. Trajectories are shown in the right panel superimposed on bathymetry maps for different seasons. Solid circles indicate the starting position of anticyclonic eddies. (a) Autumn; (b) Winter; (c) Spring; (d) Summer.

(Figure 6(b)), eddy trajectories are loosely scattered in AS west of the Laccadive ridge, and trajectories appear in the central AS having a shorter life span. They were moving in the west direction, and some trajectories decayed on the way. The direction of the trajectories is westward in the mid and west of AS. The cyclonic eddies appear travelling inside the red sea. 
In spring (Figure 6(c)), cyclonic eddies generated west of $65^{\circ} \mathrm{E}$ and were lesser in number than in winter. In summer (Figure 6(d)), trajectories showed southwest direction. Due to strong southwest monsoon wind trajectories along with western AS, no anomalies are found along the west coast of India. Cyclonic eddies along the shelf of the west coast of India were not detected. The numbers of cyclonic eddies cycles near the southern tip of India are noticed during summer, and they propagate northwest direction towards the Laccadive ridge. These eddies are known as LL. A group of eddy trajectories noticed the southern tip of India west of Sri Lanka travel northward up to $10^{\circ} \mathrm{N}$ and decays near the shallow region Laccadive ridge.

\subsubsection{Bay of Bengal (BB) Basin}

The entire $\mathrm{BB}$ is divided into three zones, as described in the previous section. The distribution of negative anomaly trajectories in the BB is shown in Figure 6 for different seasons. In the northern $\mathrm{BB}$, few trajectories were generated during winter (Figure 6(b)), and more trajectories were noticed in spring and summer travelling in the southwestward direction towards the east coast of India and decaying in autumn (Figure 6(a)). In the central BB, negative anomaly trajectories are appeared in the $5^{\circ}$ gap during autumn and winter and decays in spring, and no trajectories appear in summer (Figure 6(d)). In the southern BB, negative anomaly trajectories start appearing from winter and increases trajectories from spring to autumn travelling towards Sri Lankan east coast in the northwest direction. The BB upper layer circulation is influenced by a cyclonic flow during winter which is replaced by an anticyclonic circulation in spring. Cyclonic and anticyclonic gyres appear alternately in the western bay in summer. Sri Lanka cyclonic eddy appears at the east of Sri Lanka Island with northwestward movement and disappears in autumn under the interaction of the western boundary current of the BB [29].

\subsection{Zonal Propagating Speed of Mesoscale Anomalies}

\subsubsection{Average over Latitudinal $10^{\circ}$ Interval Box}

Figure 7 shows variations of propagating speed meridionally averaged in $10^{\circ}$ latitudinal interval box. In this Figure, U-component is averaged separately for each basin, namely AS and BB. The westward propagating speed is more towards the equator and decreases poleward as latitude increases. During autumn (Figure 7(a)), the speed varies between 5 to $10 \mathrm{~cm} \cdot \mathrm{s}^{-1}$ of anticyclonic and cyclonic at $5^{\circ} \mathrm{N}$ is common $\mathrm{AS}$ and $\mathrm{BB}$ and different in winter, spring and summer. At $15^{\circ} \mathrm{N}$, the magnitude of speed $\left(\sim 5 \mathrm{~cm} \cdot \mathrm{s}^{-1}\right)$ is lesser than $5^{\circ} \mathrm{N}$ and coincided in both basins during autumn, winter and spring and different in summer. At $25^{\circ} \mathrm{N}$, speed further reduces in both basins and is common in AS and BB. In winter (Figure 7(b)), anticyclonic speed in $\mathrm{BB}$ and AS at $5^{\circ} \mathrm{N}$ is faster than the propagating speed of cyclonic in both basins. At $15^{\circ} \mathrm{N}$, the speed of both the anomalies reduced towards the pole, and it remains equal in both basins and similar to that at $25^{\circ} \mathrm{N}$. In spring (Figure $7(\mathrm{c})$ ), the anticyclonic speed at $5^{\circ} \mathrm{N}$ is 


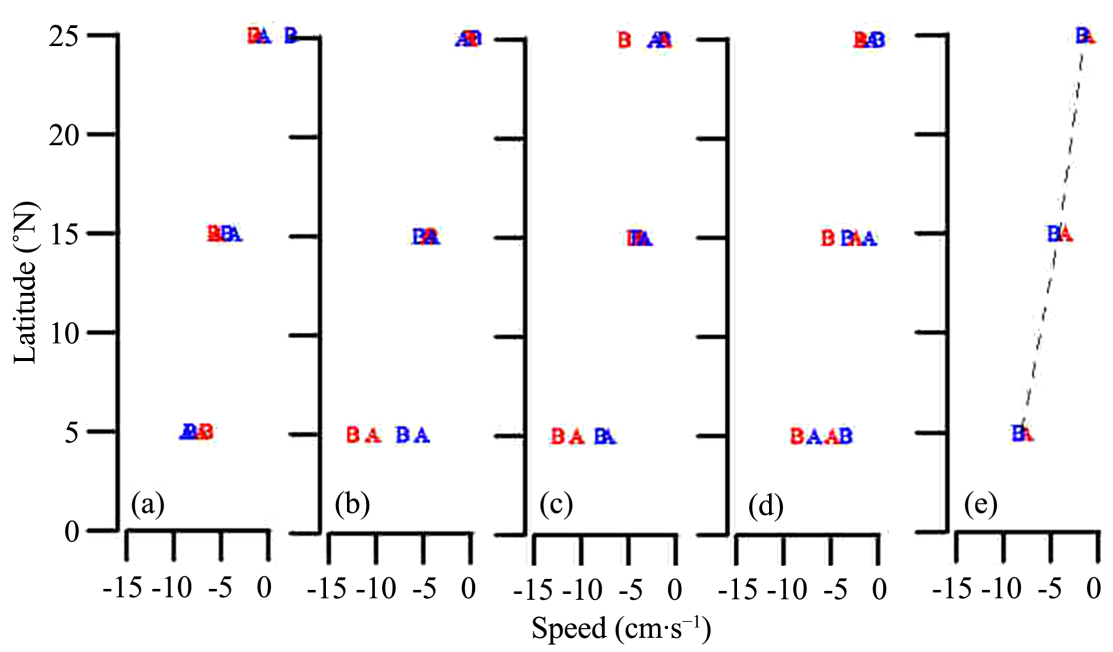

Figure 7. Meridionally variation of zonal propagating speed (U-components) averaged over $10^{\circ}$ interval latitudinal box. Symbol A stands for the Arabian Sea, and Symbol B stands for the Bay of Bengal. Red colour represents speed for anticyclonic eddies, and blue represents speed for cyclonic eddies in $\mathrm{cm} \cdot \mathrm{sec}^{-1}$ during different seasons. North of $20^{\circ} \mathrm{N}$ averages were made up to $25^{\circ} \mathrm{N}$ limit. (a) Autumn; (b) Winter; (c) Spring; (d) Summer; (e) Average.

similar in AS and BB to that in winter, whereas cyclonic is approximately equal in AS and BB. Further to the north at $15^{\circ} \mathrm{N}$ speed of both the anomalies are equal in $\mathrm{AS}$ and $\mathrm{BB}$. At $25^{\circ} \mathrm{N}$, the anticyclonic speed in $\mathrm{BB}$ is higher, and the remaining speed is equal. In summer (Figure $7(\mathrm{~d})$ ), the speed at $5^{\circ} \mathrm{N}$ anticyclonic speed of BB is greater than cyclonic speed in AS and compared to spring, BB anticyclonic speed is less. At $15^{\circ} \mathrm{N}$ speed in the two basins varies, and at $25^{\circ} \mathrm{N}$, the speed of both the anomalies is the same in the two basins. [50] detected westward propagation of $1-2 \mathrm{~cm} \cdot \mathrm{s}^{-1}$ in the eastern region $\left(32^{\circ}-42^{\circ} \mathrm{N}, 155^{\circ}-175^{\circ} \mathrm{E}\right)$ using $300 \mathrm{~m}$ depth temperature data. Using $300 \mathrm{~m}$ depth temperature data, [51] derived westward phase speed propagation of $3.8 \mathrm{~cm} \cdot \mathrm{s}^{-1}$ at $33^{\circ}-41^{\circ} \mathrm{N}$ in $140^{\circ}-$ $180^{\circ} \mathrm{E}$. [52] estimated the propagation speed of eddies as $7 \mathrm{~cm} \cdot \mathrm{s}^{-1}$, which is faster than the theoretically estimated phase speed for the first-mode baroclinic Rossby waves. By substituting the first mode internal Rossby deformation radius as 45 $\mathrm{km}$ from [53], the phase speed is estimated to be $-4.0 \mathrm{~cm} \cdot \mathrm{s}^{-1}$. The life cycle of the wave is almost 365 days (a year) which is equivalent to planetary Rossby waves. The averaged meridional zonal speed decreases at higher latitudes. The theoretical phase speed of the first mode of the baroclinic Rossby waves is quite equal to that of averaged zonal speed from the trajectories anomalies. The approaching mesoscale anomalies would be responsible for creating high variability regions in the NIO. These individual anomalies are embedded in large waves pattern travelling from east to west.

\subsubsection{Average over Longitudinal $10^{\circ}$ Interval Box}

Figure 8 shows the average speed of U-component over $10^{\circ}$ interval longitudinal box for a different season. The open circle represents the propagating speed of anticyclonic anomalies, and the solid triangle represents cyclonic anomalies. The 


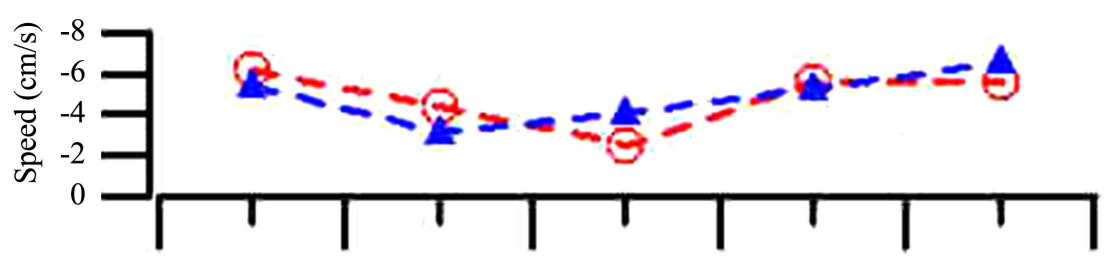

(a)

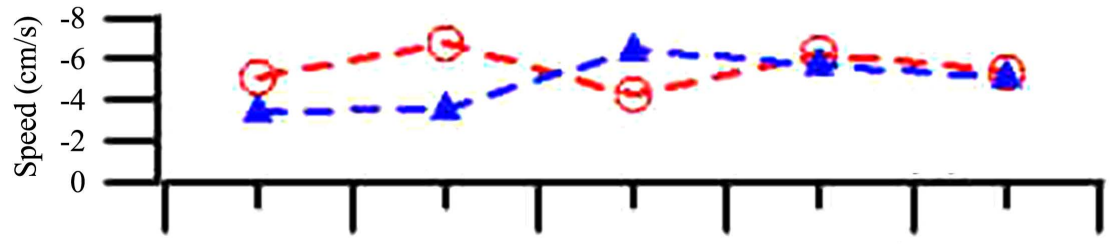

(b)

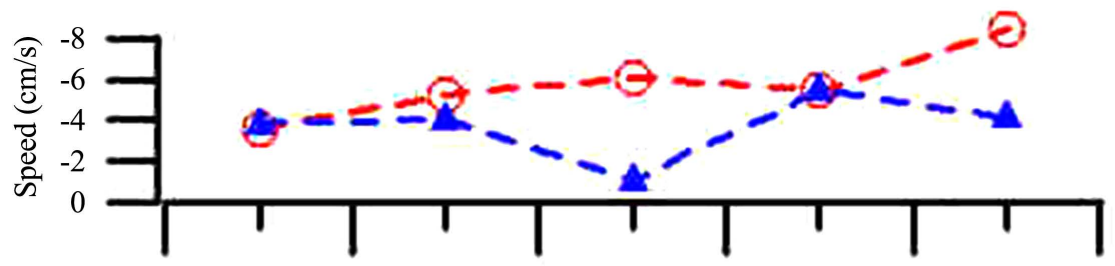

(c)

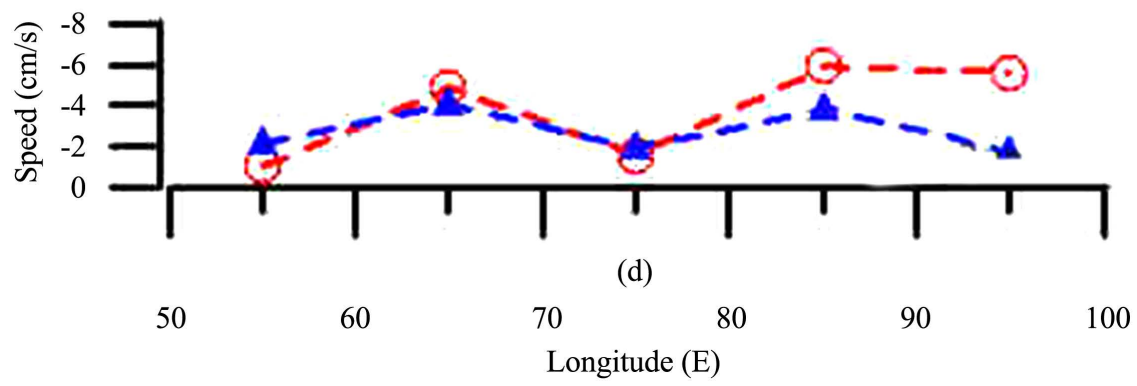

Figure 8. Zonal variation of zonal propagating speed (U-components) averaged over $10^{\circ}$ interval longitudinal box. The open circle represents speed for anticyclonic eddies, and the solid triangle represents speed for cyclonic eddies in $\mathrm{cm} \cdot \mathrm{sec}^{-1}$ for different seasons. (a) Autumn; (b) Winter; (c) Spring; (d) Summer.

dashed line connecting each average speed longitudinally has shown a wave-like propagating pattern westward. The zonal variation of speed in autumn (Figure $8(a))$ of cyclonic and anticyclonic coincides with the slowest speed of anticyclonic anomalies located at $75^{\circ} \mathrm{E}$ and cyclonic anomalies at $65^{\circ} \mathrm{E}$ as could be observed as the wave crest. The cyclonic wave crest ahead of the anticyclonic wave crest during autumn. In winter (Figure $8(\mathrm{~b})$ ) the magnitude of the zonal component in case of the anticyclonic anomalies is slightly higher at $65^{\circ} \mathrm{E}$ than the cyclonic anomalies and equal at $85^{\circ} \mathrm{E}$ onwards. The westward propagating speed of both mesoscale anomalies is equal at $85^{\circ} \mathrm{E}$ onward. In spring (Figure $8(\mathrm{c})$ ) at $75^{\circ} \mathrm{E}$, there is a reversal in the zonal component speed of both the anticyclonic and cyclonic anomalies, and at $95^{\circ} \mathrm{E}$, speed changed. In summer (Figure 8(d)) the zonal component speed of anticyclonic and cyclonic anomalies remains the 
same at $55^{\circ} \mathrm{E}, 65^{\circ} \mathrm{E}$ and $75^{\circ} \mathrm{E}$, further eastward the speed of the anticyclonic anomalies slightly higher than the cyclonic anomalies. The overall pattern of zonal speed in the NIO in summer formed the propagation of the wave in a westward direction. Complete wave formation is observed during summer with the westward propagating speed. In summer (Figure 8(d)), a perfect westward propagating wave formed with crest and trough. Since the water equatorward of the central latitude has higher counterclockwise angular momentum than the water poleward of the central latitude, the equatorward water will turn poleward with a slightly smaller radius of curvature than that of the poleward water. Due to the latitude variation of the Coriolis parameter, this effect causes all eddies, warm-core and cold-core, to propagate westwards. The propagation speed is estimated at approximately $7 \mathrm{~cm} \cdot \mathrm{sec}^{-1}$, which is much faster than the phase speed theoretical estimated for the barotropic first mode Rossby waves. [16] attributed $87 \%$ of the seasonal hydrographic variance in this region to first- and second-mode Rossby waves.

\section{Conclusion}

The present study attempted to detect individual mesoscale eddy trajectories manually and understand seasonal changes in term of their phase speed and to know the causative factor for high variability region in the NIO. The total number of counts of the individual trajectories varies in each season and reversing its count in spring/summer. The seasonal individual mesoscale anomalies namely cyclonic and anticyclonic eddy showed propagating tendency as westward or southwestward. The positive anomalies trajectories in the AS generated in winter along the west coast of the India move westward in spring/summer covering more distance and finally accumulated along with Somalia, Arabia coast. A group of positive anomalies trajectories observed at the southern tip of India and west of Laccadive Ridge during winter to spring could be associated with $\mathrm{LH}$. The trajectories of negative anomalies start generating away from the continental shelf of India in winter and finally travel along the coast of Somalia Arabia during spring, summer, and autumn. The group of negative anomalies trajectories appears generating at the southern tip of India during summer, and intensify in autumn could be associated with the LL. The flow pattern of trajectories in the $\mathrm{BB}$ is complex to explain as compared to the AS basin. The positive (and negative) anomalies in the northern BB appear in winter near the Burma continental shelf travelling in the southwest direction and decays in summer/autumn (autumn) in the shallow region. The positive anomalies trajectories in the central BB appear along the continental shelf of Andaman and Nicobar plateau during winter and propagate westward. The negative anomaly trajectories appear in a gap of $5^{\circ}$ during autumn to winter and decay in spring, no trajectories appear in summer. In the southern $\mathrm{BB}$, the positive (negative) anomalies trajectories travelling towards east coast Sri Lanka in summer to winter (winter) generate west of $90^{\circ} \mathrm{E}$ and the number of trajectories increases from spring to autumn travel- 
ling towards Sri Lankan east coast. The averaged westward propagating zonal speed over $10^{\circ}$ latitudinal interval is decreased poleward and at $5^{\circ} \mathrm{N}$, zonal speed is common in autumn and different in winter, spring and summer. The zonal speed is approximately the same in both the basins at $15^{\circ} \mathrm{N}$ and $25^{\circ} \mathrm{N}$. Zonally averaged speed over $10^{\circ}$ longitudinal interval box has shown seasonal changes and wave like pattern formed on annual time scale. The zonal speed is comparable with the theoretical phase speed of the baroclinic first-mode long Rossby wave. The complete wave formation is observed during summer. Therefore it is concluded that anticyclonic (warm-core) and cyclonic (cold-core) mesoscale anomalies (eddies), which are embedded into the large waves like phenomenon (Rossby waves), are responsible for creating high variability and EKE in the region of NIO along the western boundaries. Further studies are required to understand the role of mesoscale eddies in ocean circulations.

\section{Acknowledgements}

I express my gratitude to the Secretary, MoES and Director, NCPOR, for their support and encouragement to carry out this research work. Also, sincere thanks to ESA's (ERS-1 and ERS-2 data), CNES/NASA (TOPEX/POSEIDON data), and CLS "MSLA" product provided by AVISO altimetry; NCAR for providing Global Ocean Depth and Land Elevation to carry out current research work.

\section{Conflicts of Interest}

The author declares no conflicts of interest regarding the publication of this paper.

\section{References}

[1] Tomczak, M. and Godfrey, J.S. (1994) Regional Oceanography: An Introduction. Pergamon, Oxford, 422.

[2] Bauer, S., Hitchcock, G.L. and Olson, D.B. (1991) Influence of Monsoonally Forced Ekman Dynamics of Upper Surface Layer Depth and Phytoplankton Biomass Distribution in the Arabian Sea. Deep Sea Research, Part-I, 38, 531-533. https://doi.org/10.1016/0198-0149(91)90062-K

[3] Madhupratap, M., Prasanna Kumar, S., Bhattathiri, P.M.A., Dileep Kumar, M., Raghukumar, S., Nair, K.K.C. and Ramaiah, N. (1996) Mechanism of the Biological Response to Winter Cooling in the Northeastern Arabian Sea. Nature, 384, 549-552. https://doi.org/10.1038/384549a0

[4] Lee, C.M., Jones, B.H., Brink, K.H. and Fischer, A.S. (2000) The Upper Ocean Response to Monsoonal Forcing in the Arabian Sea: Seasonal and Spatial Variability. Deep Sea Research, Part II, 47, 1177-1226. https://doi.org/10.1016/S0967-0645(99)00141-1

[5] Cutler, A.N. and Swallow, S.C. (1984) Surface Currents of the Indian Ocean (to $25^{\circ} \mathrm{S}, 100^{\circ} \mathrm{E}$ ): Compiled from Historical Data Archived by the Meteorological Office. Report No. 87. Institute of Oceanographic Sciences, Broadchill, UK.

[6] Shetye, S.R., Shenoi, S.S.C., Gouveia, A.D., Michael, G.S., Sundar, D. and Nampoothiri, G. (1991) Wind-Driven Coastal Upwelling along the Western Boundary of the 
Bay of Bengal during the Southwest Monsoon. Continental Shelf Research, 11, 1397-1408. https://doi.org/10.1016/0278-4343(91)90042-5

[7] Wyrtki, K. (1973) An Equatorial Jet in the Indian Ocean. Science, 181, 262-264. https://doi.org/10.1126/science.181.4096.262

[8] Yih, Y., Liu, C.-T., Hu, J.-H. and Koga, M. (1999) Taiwan Current (Kuroshio) and Impinging Eddies. Journal of Oceanography, 55, 609-617. https://doi.org/10.1023/A:1007892819134

[9] Perigaud, C. and Delecluse, P. (1992) Annual Sea Level Variations in the Southern Tropical Indian Ocean from Geosat and Shallow-Water Simulations. Journal of Geophysical Research, 97, 20169-20178. https://doi.org/10.1029/92JC01961

[10] Ichikawa, K. and Imawaki, S. (1994) Life History of a Cyclonic Ring Detached from the Kuroshio Extension as Seen by the Geosat Altimeter. Journal of Geophysical Research, 99, 15953-15966. https://doi.org/10.1029/94JC01139

[11] Ebuchi, N. and Hanawa, K. (2000) Mesoscale Eddies Observed by TOLEX-ADCP and TOPEX/POSEIDON Altimeter in the Kuroshio Recirculation Region South of Japan. Journal of Oceanography, 56, 43-57. https://doi.org/10.1023/A:1011110507628

[12] Yasuda, I., Itoh, S., Shimizu, Y., Ichikawa, K., Ueda, K., Honma, T., Uchiyama, M., Watanabe, K., Suno, N., Tanaka, K. and Koizumi, K. (2000) Cold Core Anticyclonic Eddies South of Bussol Strait in the Northwestern Subarctic Pacific. Journal of Physical Oceanography, 30, 1137-1157. https://doi.org/10.1175/1520-0485(2000)030<1137:CCAESO >2.0.CO;2

[13] Babu, M.T., Prasanna Kumar, S. and Rao, D.P. (1991) A Subsurface Cyclonic Eddy in the Bay of Bengal. Journal of Marine Research, 49, 403-410. https://doi.org/10.1357/002224091784995846

[14] Swallow, J.C., Molinari, R.L., Bruce, J.C., Brown, O.B. and Robert, H.E. (1983) Evans, Development of Near-Surface Flow and Water Mass Distribution in Somali Basin in Response to the Southwest Monsoon of 1979. Journal of Physical Oceanography, 3, 1398-1415.

[15] Chelton, D.B., Schlax, M.G. and Samelson, R.M. (2011) Global Observations of Nonlinear Mesoscale Eddies. Progress in Oceanography, 91, 167-216. https://doi.org/10.1016/j.pocean.2011.01.002

[16] Brandt, P., Stramma, L., Schott, F., Fischer, J., Dengler, M. and Quadfasel, D. (2002) Annual Rossby Waves in the Arabian Sea from TOPEX/POSEIDON Altimeter and in Situ Data. Deep-Sea Research Part II: Topical Studies in Oceanography, 49, 1197-1210. https://doi.org/10.1016/S0967-0645(01)00166-7

[17] McCreary, J.P., Kundu, P.K. and Molinari, R.L. (1993) A Numerical Investigation of Dynamics, Thermodynamics and Mixed-Layer Processes in the Indian Ocean. Progress in Oceanography, 31, 181-244. https://doi.org/10.1016/0079-6611(93)90002-U

[18] Shankar, D. and Shetye, S.R. (1997) On the Dynamics of the Lakshadweep High and Low in the Southeastern Arabian Sea. Journal of Geophysical Research, 102, 1255112562. https://doi.org/10.1029/97JC00465

[19] Subrahmanyam, B., Robinson, I.S., Blundell, J.R. and Challenor, P.G. (2001) Indian Ocean Rossby Waves Observed in TOPEX/POSEIDON Altimeter Data and Model Simulations. International Journal of Remote Sensing, 22, 141-167. https://doi.org/10.1080/014311601750038893

[20] Tozuka, T. and Yamagata, M.N.T. (2014) Influence of the Reflected Rossby Waves on the Western Arabian Sea Upwelling Region. Journal of Physical Oceanography, 
44, 1424-1438. https://doi.org/10.1175/JPO-D-13-0127.1

[21] Trott Corinne, B., Subrahmanyam, B., Chaigneau, A. and Delcroix, T. (2018) Eddy Tracking in the Northwestern Indian Ocean during Southwest Monsoon Regimes. Geophysical Research Letters, 45, 6594-6603. https://doi.org/10.1029/2018GL078381

[22] Piontkovski, S.A., Al-Tarshi, M.H., Al-Ismaili, S.M., Al-Jardani, S.S.H. and Al-Alawi, Y.H.A. (2019) Inter-Annual Variability of Mesoscale Eddy Occurrence in the Western Arabian Sea. International Journal of Oceans and Oceanography, 13, $1-23$.

[23] Dube, S.K., Luther, M.E. and O’Brien, J.J. (1990) Relationships between Interannual Variability in the Arabian Sea and Indian Summer Monsoon Rainfall. Meteorology and Atmospheric Physics, 44, 153-165. https://doi.org/10.1007/BF01026816

[24] Ali, M.M. and Sharma, R. (1998) Studying Indian Ocean Typical Phenomena Using TOPEX Observations. Marine Geodesy, 21, 193-201. https://doi.org/10.1080/01490419809388135

[25] Nuncio, M. and Prasanna Kumar, S. (2012) Life Cycle of Eddies along the Western Boundary of the Bay of Bengal and Their Implications. Journal of Marine Systems, 94, 9-17. https://doi.org/10.1016/j.jmarsys.2011.10.002

[26] Vidya, P.J. and Prasanna Kumar, S. (2013) Role of Mesoscale Eddies on the Variability of Biogenic Flux in the Northern and Central Bay of Bengal. Journal of Geophysical Research, (C: Oceans), 118, 5760-5771. https://doi.org/10.1002/jgrc.20423

[27] Cui, W., Yang, J. and Ma, Y. (2016) A Statistical Analysis of Mesoscale Eddies in the Bay of Bengal from 22-Year Altimetry Data. Acta Oceanologica Sinica, 35, 16-27. https://doi.org/10.1007/s13131-016-0945-3

[28] Greaser, S.R., Subrahmanyam, B., Trott, C.B. and Roman-Stork, H.L. (2020) Interactions between Mesoscale Eddies and Synoptic Oscillations in the Bay of Bengal during the Strong Monsoon of 2019. Journal of Geophysical Research: Oceans, 125, 1-29. https://doi.org/10.1029/2020JC016772

[29] Vinayachandran, P.N., Masumoto, Y. and Mikawa, T. (1999) Intrusion of the Southwest Monsoon Current into the Bay of Bengal. Journal of Geophysical Research: Oceans, 104, 11077-11085. https://doi.org/10.1029/1999JC900035

[30] Yu, L.S., O’Brien, J.J. and Yang, J.Y. (1991) On the Remote Forcing of the Circulation in the Bay of Bengal. Journal of Geophysical Research: Oceans, 96, 20449-20454. https://doi.org/10.1029/91JC02424

[31] Le Traon, P.Y., Gaspar, P., Bouyssel, F. and Makhmara, H. (1995) Using TOPEX/ Poseidon Data to Enhance ERS-1 Data. Journal of Atmospheric and Oceanic Technology, 12, 161-170. https://doi.org/10.1175/1520-0426(1995)012<0161:UTDTED>2.0.CO;2

[32] Le Traon, P.Y., Nadal, F. and Ducet, N. (1998) An Improved Mapping Method of Multi-Satellite Altimeter Data. Journal of Atmospheric and Oceanic Technology, 25, 522-534. https://doi.org/10.1175/1520-0426(1998)015<0522:AIMMOM>2.0.CO;2

[33] Levitus, S. and Boyer, T.P. (1994) World Ocean Atlas 1994, Volume 4: Temperature. NOAA Atlas NESDIS, 117.

[34] Levitus, S., Burgett, R. and Boyer, T.P. (1994) World Ocean Atlas 1994, Vol. 3, Salinity. NOAA Atlas NESDIS, 99.

[35] Pednekar, S.M., Koga, M. and Yasuhiro, S. (2001) Trajectory of Mesoscale Eddies East of Okinawa Island Was Observed Using Satellite Altimetry. Japan Oceanogra- 
phy Society Conference on Oceanography, Shimizu, 22-26 September 2001, 30-32.

[36] Roemmich, D. and Wunsch, C. (1982) On Combining Satellite Altimetry with Hydrographic Data. Journal of Marine Research, 40, 605-619.

[37] Pond, S. and Pickard, G.L. (1983) Introductory Dynamical Oceanography. 2nd Edition, Pergamon Press, Oxford. https://doi.org/10.1016/B978-0-08-057054-9.50007-9

[38] Qiu, B. (1999) Seasonal Eddy Field Modulation of the North Pacific Subtropical Countercurrent: TOPEX/Poseidon Observations and Theory. Journal of Physical Oceanography, 29, 2471-2486. https://doi.org/10.1175/1520-0485(1999)029<2471:SEFMOT>2.0.CO;2

[39] Wyrtki, K., Magaard, L. and Hager, J. (1976) Eddy Energy in the Oceans. Journal of Geophysical Research, 81, 148-227. https://doi.org/10.1029/JC081i015p02641

[40] Shenoi, S.S.C., Shankar, D. and Shetye, S.R. (1999) On the Sea Surface Temperature High in the Lakshadweep Sea before the Onset of Southwest Monsoon. Journal of Geophysical Research, 104, 15703-15712. https://doi.org/10.1029/1998JC900080

[41] Richardson, P.L. (1983) Eddy Kinetic Energy in the North Atlantic from Surface Drifters. Journal of Geophysical Research, 88, 4355-4367. https://doi.org/10.1029/JC088iC07p04355

[42] Qiu, B. (1995) Variability and Energetics of the Kuroshio Extension and Its Recirculation Gyre from the First 2-Year TOPEX Data. Journal of Physical Oceanography, 25, 1827-1842. https://doi.org/10.1175/1520-0485(1995)025<1827:VAEOTK>2.0.CO;2

[43] Pednekar, S.M., Suwa, J. and Yasuhiro, S. (2002) Rossby Wave Propagation in the Indian Ocean Based on Time-Space Correlation Method from Satellite Altimetry. Japan Oceanography Society Conference on Oceanography, Shinagawa, 27-31 March 2002, 74-76.

[44] Bruce, J.G., Johnson, D.R. and Kindle, J.C. (1994) Evidence for Eddy Formation in the Eastern Arabian Sea during the Northeast Monsoon. Journal of Geophysical Research, 99, 7651-7664. https://doi.org/10.1029/94JC00035

[45] Bruce, J.G., Kipdle, J.C., Kantha, L.H., Kerling, J.L. and Bailey, J.F. (1998) Recent Observations and Modeling in the Arabian Sea Luccadive High Region. Journal of Geophysical Research, 103, 7593-7600. https://doi.org/10.1029/97JC03219

[46] Prasad, T.G., Ikeda, M. and Prasanna Kumar, S. (2001) Seasonal Spreading of the Persian Gulf Water Mass in the Arabian Sea. Journal of Geophysical Research, 106, 17059-17071. https://doi.org/10.1029/2000JC000480

[47] An, H., Shim, K. and Shin, H.R. (1994) On the Warm Eddies in the Southwestern Part of the East Sea (the Japan Sea). Journal of the Korean Society of Oceanography, 29, 152-163.

[48] Toba, Y., Kawamura, H., Yamashita, F. and Hanawa, K. (1984) Structure of Horizontal Turbulence in the Japan Sea. In: Ichiye, T., Ed., Ocean Hydrodynamics of Japan and East China Seas, Elsevier Science Publishers, Amsterdam, 317-332. https://doi.org/10.1016/S0422-9894(08)70309-X

[49] Murty, V.S.N., Sarma, Y.V.B., Rao, D.P. and Murty, C.S. (1992) Water Characteristics, Mixing and Circulation in the Bay of Bengal during the Southwest Monsoon. Journal of Marine Research, 50, 207-228. https://doi.org/10.1357/002224092784797700

[50] Mizuno, K. and White, W.B. (1983) Annual and Interannual Variability in the Kuroshio Current System. Journal of Physical Oceanography, 13, 1847-1867. https://doi.org/10.1175/1520-0485(1983)013<1847:AAIVIT>2.0.CO;2 
[51] Bernstein, R.L. and White, W.B. (1981) Stationary and Travelling Mesoscale Perturbations in the Kuroshio Extension Current. Journal of Physical Oceanography, 11, 692-704. https://doi.org/10.1175/1520-0485(1981)011<0692:SATMPI >2.0.CO;2

[52] Ebuchi, N. and Hanawa, K. (2001) Trajectory of Mesoscale Eddies in the Kuroshio Recirculation Region. Journal of Oceanography, 57, 471-480. https://doi.org/10.1023/A:1021293822277

[53] Emery, W.J., Lee, W.G. and Magaard, L. (1984) Geographic and Seasonal Distributions of Brunt-Vaisala-Frequency and Rossby Radii in the North Pacific and North Atlantic. Journal of Physical Oceanography, 14, 294-317. https://doi.org/10.1175/1520-0485(1984)014<0294:GASDOB>2.0.CO;2 